\title{
Study on the Psychological Crisis of New Generation of Migrant Workers
}

\author{
Ge Shaolin $^{1}$ Han Quanfang ${ }^{2}$ \\ 1,2School of Public Management, Yunnan University of Economics and Finance, Kunming, \\ P.R.China, 650221 \\ (1.geshaolin72@yahoo.com.cn; 2.hqfang666@163.com)
}

\begin{abstract}
The article uses the method of questionnaire investigation, depends on the base of literature review of new generation of migrant workers since the China's reform and opening up, and analyzes the major industry distribution and psychological healthy situation of new generation of migrant workers in Kunming. The study finds that the features of new generation of migrant workers are the wide resource, young ages, and the main is unmarried. The new generation of migrant workers who has a lower education level, older ages, worse healthy, longer working time and stronger social exclusion are easier to appear psychological crisis. Finally, I recommend some suggestions for the psychological healthy of new generation of migrant workers in the ways of psychological counseling, policies and measures, employment training and social justice.
\end{abstract}

Keywords: The new generation of migrant workers, Psychological Crisis, Psychological counseling, Social justice

\section{Introduction}

Since China's reform and opening up, the vast farmers steeply have gained the freedom of flowing and started to move to city for jobs, the phenomenon of "Seasonal Migration of Peasants" appeared, and it caused the attention of the society widely. The study shows that migrant workers have already gone through two generations and the new generation of migrant workers has already become the main part of migrant workers now. [1]The new generation of migrant workers mainly refers to the1980s and the 1990s. The group of these people has 100 million members which occupies $60 \%$ of the 150 million Chinese migrant workers. Jan 1st 2010, "On balance urban and rural development, farther tamp foundation for agricultural and rural development certain opinions" which the State Council set, firstly used the wording that "the new generation of migrant workers", requested resolving the new generation of migrant workers problems and making the new generation of migrant workers residential.

Recently, New generation of migrant workers problems obviously appeared in China, from "Foxconn 12 jumps" to new generation of migrant workers suicide for salary, and it exposed that the new generation of migrant workers face a psychological crisis. It is important to improve new generation of migrant workers psychological intervention, and improve the new generation of migrant workers living environment to the promotion of urban community building and build a harmonious society.

Chunguang Wang defines the new generation of rural flow population from five dimensions which are the features of times and ages, the education feature, farming experience and the motivation of going out. [2]Some scholars summarize that the new generation of migrant workers feature is "Three high and one low" which are high education level, high career expectation, high requirement of substance and spirit sharing and low wage tolerance. [3] Xiaorong Xie etc think that the new generation of migrant workers has two main features. Firstly, it is the motivation of going out both economy form and life form. Secondly, the new generation of migrant workers has a higher expectation of wages and a strong awareness and ability of "bargaining" 
so that they have stronger fluidity and selectivity. [4]

Many Chinese Scholars conducted a survey of the different parts of the psychological health of migrant workers. The survey results show that the psychological health of the local migrant workers below the national average. [5] [6] Wenbo Dou thinks that migrant workers pouring into the city's are lack of confidence in the city public exchange comparing with urban residents, have serious closed psychology which may lead to suppressed emotions, and it results in psychological imbalance and problems. [7] Jianfeng Liu thinks that psychological problems which affect the generation of migrant workers can be attributed to the subjective and objective aspects. [8] Hongwei $\mathrm{Hu}$ thinks that the psychological problems of the new generation of migrant workers are frequent and they rarely seek help. Age, health, working hours, the enterprise management level, and social exclusion are the main influencing factors. [9] Xiao Bao believes that there exist mainly self-esteem and depression, closed and lonely dissatisfaction and resentment, hatred and revenge, a series of psychological problems in the "new generation" of migrant workers. [10]

2. A case of mental health status of the new generation of migrant workers in Kunming

\subsection{The main industry distribution of the new generation of migrant workers}

Table 1 shows that, in comparison with the last generation of migrant workers, the new generation of migrant workers in Kunming mainly converges in manufacture markets. To be more specific, the rates of migrant workers who are into the manufacture and architecture are $40.2 \%$ and $16.8 \%$, respectively. But the new generation of migrant workers who are labored in manufacture have increased to the rates of $47.2 \%$, and the rates of workers in architecture is only 7.2\%.Meanwhile, the proportions of accommodation and restaurant business, communities service and other catering service fields of the new generation are surging as well .Compared with anterior generation, the rates is extending by $2.7 \%$ and $3.6 \%$, respectively. This indicate that the determinations of the workers' job selections is more than the salary level the job contains, they now also take job circumstances and professional prospect into consideration. The new generation of migrant workers tends to choose more decent, safe and promising occupations.

\begin{tabular}{l|lll}
\hline \multicolumn{1}{c|}{ Industry Distribution } & \multicolumn{3}{c}{ Migrant workers } \\
& Total & The Old Generation of & The New Generation of \\
& & Migrant Workers & Migrant Workers \\
\hline Manufacturing & 40.2 & 28.2 & 47.2 \\
Construction & 16.8 & 33.2 & 7.2 \\
Traffic, transport, storage and post & 5.6 & 6.3 & 5.3 \\
Wholesale and retail trades & 6.9 & 6.8 & 9.1 \\
Hotels and catering services & 8.1 & 7.5 & 10.2 \\
Services to households and other services & 12.1 & 8.6 & 12.2 \\
Others & 10.3 & 9.4 & 8.8 \\
Total & 100 & 100 & 100 \\
\hline
\end{tabular}

Table 1: The Major Sectors of Distribution of The New Generation of Migrant Workers

\subsection{The mental heath condition of the new generation peasant worker}

Table 2 shows that new generation of migrant workers in general have insomnia, exhaustion, psychological stress, loneliness, despair and other psychological symptoms, accounted for $76.3 \%, 93.5 \%, 96.4 、 82.3 \%, 80.1 \%$ 、
$39.6 \%$,respectively. About $60 \%$ of them need a lot of overtimes, making part of them to endure the huge pressure form work. The proportion for feeling enormous pressure and feeling a little pressure among them is $10.6 \%$ and $30.2 \%$. The new generation of migrant workers has to work 26days monthly, and 9hours daily in average. And it didn't show any significant 
differences with other age groups. In the new generation of migrant workers, the ratio of the average eight-hour day was $58.6 \%, 38.8 \%$ average work 9-10 hours a day, and another

\begin{tabular}{|l|c|c|c|}
\hline \multirow{2}{*}{$\begin{array}{l}\text { Psychological } \\
\text { Health Index }\end{array}$} & \multicolumn{3}{|c|}{$\begin{array}{l}\text { In the Life and Work Have Any of } \\
\text { the Following Circumstances }\end{array}$} \\
\cline { 2 - 4 } & Yes (\%) & No(\%) & Total(\%) \\
\hline Insomnia & 76.3 & 23.7 & 100 \\
\hline Exhaustion & 93.5 & 6.5 & 100 \\
\hline Stress & 96.4 & 3.6 & 100 \\
\hline Loneliness & 82.3 & 17.7 & 100 \\
\hline Poverty & 86.4 & 13.6 & 100 \\
\hline Future Confusion & 80.1 & 19.9 & 100 \\
\hline Despair & 39.6 & 60.4 & 100 \\
\hline
\end{tabular}

Table 2 :The new generation of migrant workers psychological healthy situation

$2.6 \%$ of the new generation of migrant workers, the average daily need to work 11 to 12 hours. As with the previous generation, the new generation of migrant workers is still assiduous.

\section{Data and Methods}

3.1 Data

\begin{tabular}{|l|c|c|c|c|c|}
\hline \multicolumn{1}{|c|}{ Variable } & Frequency & Mean & $\begin{array}{c}\text { Standard } \\
\text { deviation }\end{array}$ & Minimum & Maximum \\
\hline sex & 280 & 0.47 & 0.5 & 1 & 2 \\
\hline age & 280 & 23.52 & 3.48 & 18 & 35 \\
\hline health & 270 & 3.79 & 0.92 & 1 & 5 \\
\hline eduyear & 280 & 11.01 & 3.06 & 3 & 19 \\
\hline exp & 271 & 4.30 & 2.72 & 0.07 & 14 \\
\hline teclevel & 269 & 1.96 & 0.90 & 1 & 4 \\
\hline worktime & 279 & 9.42 & 1.86 & 4 & 14.2 \\
\hline wage & 280 & 1659.26 & 1183.65 & 300 & 10526 \\
\hline management & 276 & 3.00 & 0.82 & 1 & 5 \\
\hline security & 271 & 0.15 & 0.36 & 0 & 1 \\
\hline henviroment & 280 & 2.92 & 0.94 & 1 & 5 \\
\hline hexp & 279 & 2.50 & 0.80 & 1 & 5 \\
\hline colleague & 276 & 3.67 & 0.80 & 1 & 5 \\
\hline rejectl & 269 & 2.17 & 0.73 & 1 & 3 \\
\hline
\end{tabular}

Table 3 the new generation of migrant workers Independent variables of the psychological crisis
The data used in this article came from "the social integration research of the new migrant workers" in 2001. The survey content about this generation covers their psychological conditions, social-demographic characteristics, family status, corporate status, community environmental conditions and social relationship etc. All of these provide an abundant resource of figures.

\subsection{Sample}

This study is using a combination of stratified random sampling and cluster sampling to select respondents. The questionnaires were distributed 300 copies in total of which 280 valid questionnaires, the recovery rate of 93.3\%.

\subsection{Statistical Methods}

In this study, sample data entry using SPSS 17.0 statistical software, using descriptive statistics, regression analysis and other methods.

\subsection{Variable}

The dependent variable is psychological conditions among the newly migrant workers in this study. And the independent variable includes sex, age, health, eduyear, leclevel, worktime, wage,management, security, henviroment, hexp, colleague, rejectl.(table3). 


\section{Results}

The new generation spring from an extended scope. Also they have a young age 23.52 in average, $82.1 \%$ for non-only children. When it comes to education, it is obvious that newly one is higher than previous one. The proportion of primary and secondary education in this generation has substantially reduced, and the portion of junior high school has proliferated dramatically. As for the marital status in this generation, there are more unmarried members, accounting for $81.5 \%$; married accounted for $16.4 \%$.

Lower level of education, more psychological problems produced among these workers. On the other hand, in line with expectation, workers with higher education level have a more intensive tendency of psychological talking and better psychological wiliness and channel about talking.

It tends to be an increasing function between age and the probability of psychological problems, which means elder the workers are higher the symptoms will be caused. On the other hand, elder workers are more likely to talk about their emotional states.

It tends to be a decreasing function between physical condition and the probability of psychological problems of new generation of migrant workers. It is worth to pay attention to the people who are in weak physical conditions and lacked of tendency of talking.

The migrant workers who are in the long duration of working can easily get psychological problems. However, there is no any higher talking tendency toward a person or an institution for help in reciprocal.

The repugnance faced by new generation of migrant workers may galvanize the psychological problems. Meanwhile, it may cause lower tendency of talking including talking to an institution.

\section{Conclusion}

The new generation of migrant workers is the specific product of China's industrialization, urbanization, market, modernization process. In conflict with the urban mainstream population, the flowing migrant workers are in a marginalized state. Researches put forward that immigrant groups are in the margins of society and marginalized status makes the new immigrants are easily exposed to damage the psychological health of the environment and conditions. [11] Based on the above findings, this article proposes a number of thinking.

Take full advantage of the professional psychological organizations to provide counseling to the generation of migrant workers. Professional psychological organizations need to assume the responsibility to help the new generation of migrant workers to solve problems, and they not only to help to seek the help of the new generation of migrant workers, but also take the initiative to understand the psychological status of the new generation of migrant workers, concern about their life and work, and find problems and solve them timely.

Develop new generation of migrant workers positive psychological capacity. Positive psychology is a thought which is the rise of Western psychology in the late 20th century with a positive psychological ability including: self-efficacy, optimism, emotional intelligence, subjective well-being etc.

Improve the system and implement policy measures which will help to improve the situation of the new generation of migrant workers. The government should clear away institutional barriers caused by the negative psychology of the migrant workers immediately, accelerate the formulation of policies to improve their vulnerable situation, and vigorously publicize and implement these policies, so that they feel the care and concern of the state and society.

Train the new generation of migrant workers and improve their overall quality. Government, business and social forces should unite to form a new generation of migrant workers in vocational schools, government-led, social training institutions to supplement the training mode, to enhance their vocational skills.

Provide the need of more social justice environment for the new generation of migrant workers. The society needs to see the effect that the new generation of migrant workers makes for urban construction. They need more attention and respect, many urban people should also understand and care for them, give them more respect and it will let them have more hope and power. The society will have more justice, the life of migrant workers will be happier, and the society will be more harmonious. 


\section{Acknowledgments:}

This article sported by Yunnan Province Philosophy Social Science Planning Projects ( NO.Yb201124) , Foundation of Yunnan University of Economics and Finance (No.Yc10d007), Ministry of Education of Humanities and Social Sciences Youth Fund (No.12yjc840007), Ministry of Education, Humanities and Social Sciences Western and Border Areas Fund (No.11xja840002).

\section{References}

[1]He Lei. See Through from Chinese Cenozoic Era Laborers [J]. Forum of Village, 2005,3(18):22-23(In Chinese).

[2] Wang Chunguang. Social Identity of the New Generation of Rural Hobo and Merger of Urban and Rural[J]. Sociological Studies ,2011,12 (3): 66-69(In Chinese).

[3] Wang Zhenghong.The Phenomenon of Shortage of Migrant Workers and Cenozoic Era Laborers' Rational Chooses[J]. Theory Journal, 2006,6(9): 75(In Chinese).

[4] Xie Xiaorong, Wangzheng. Shortage of New Generation Farmer Workers in Guangdong: Sources and Countermeasures [J]. Huazhong Agricultural University Newspaper (JCR Social Science Edition), 2006,6(4):23(In Chinese).

[5] Sun Jianzhong, Li Manqin, Wu Lanlan. Mental Health Survey of An Hui's Migrant Workers [J]. Health Psychology Journal, 1999,8 (1) : 80-81(In Chinese).

[6] Hu Ronghua,Ge Minggui.The Survey of Mental Health Status for 408 Peasant Laborers [J].Chinese Health Service Management, 2008,3 ( 3 ) : 196-198(In Chinese).

[7] Dou Wengbo.The Shallow Analysis of Migrant Workers Situations in Psychology [J] Chinese Business (second half of the mouth), 2010,6 (7) (In Chinese).

[8] Liu Jianfeng.Psychological work pressure relief About Migrant Workers. The University of Ji Xi Newspaper, 2007,2 (6) (In Chinese).

[9] Hu Hongwei, Wang Jinpeng ,Cao; Yang.The Problem of Chinese Cenozoic Era Laborers and the Actions of Seeking Help Research [J]. People of Northwest,2011,3（5）: 27. (In Chinese)
[10] Bao Xiao.The Psychical Hinder and Debugging Countermeasure of The People Who were born in 1980s [J]. Economy Proficient, 2008,6(6): 54-55. (In Chinese).

[11]Aderete E,Vega W A,Kolody B,et al.Effeets of time in the United Staes and Indian ethnieity on DSM- 111-R Psyehiatric disorders among MeXiean Amerieans in California [J]. J Nev Ment Dis, 2000, 188(2):90-100. 